\title{
APONTAMENTOS SOBRE A CLASSE TRABALHADORA BRASILEIRA NOS PROCESSOS DE REESTRUTURAÇÕES DO TRABALHO*
}

Alba Tereza B. de Castro

\section{O capitalismo dependente brasileiro no século XXI: di- lemas do desenvolvimento em meio às políticas de ajuste}

A crise de 1970 constitui um marco no processo de desenvolvimento do capitalismo mundial. O conjunto de países de economia de mercado (centrais e periféricos) vivenciou, de forma diferenciada, os impactos desta crise, desenvolvendo distintas políticas de ajuste sob a inspiração do neoliberalismo. A aproximação entre centro e periferia, desta forma tão imbricada, expressa movimentos inéditos de conformação do capitalismo enquanto sistema mundial, com mudanças profundas nas relações de dominação e dependência entre os países. A rigor, evidencia-se, neste processo, a gestação de uma nova etapa do capitalismo dependente no Brasil, que viria a ser impulsionada tardia e intensamente pelo aprofundamento de reformas neoliberais a partir da década de 1990, segundo os ditames do Consenso de Washington.

Tais processos de mudanças substantivas do sistema do capital ensejam, no final do século XX e início do século XXI, a reconfiguração de fenômenos estruturais, inerentes à formação histórica da sociedade brasileira: a dependência e o desenvolvimentismo, sob novos formatos, com novas leituras, adaptações e interesses. O que era antigo é retomado sob novos ares nos rearranjos macroeconômicos da economia capitalista mundial em crise.

Para adentrar nas reconfigurações contemporâneas da dependência no Brasil, cabe uma incursão panorâmica nos percursos da economia brasileira no âmbito do capitalismo mundial. No seu livro Brasil Delivery, Lêda Paulani chama de servidão a atual configuração da dependência brasileira, associada à financeirização mundial (Paulani, 2008). É inconteste que, a partir de 1973, todos os países passaram a depender crescentemente de fluxos de capitais financeiros. Começava, nesta década, a se gestar o movimento de internacionalização do capital, através de vínculos cada vez mais estreitos entre o capital externo e a estru-

*DOI - 10.29388/978-65-86678-20-8-0-f.147-162 
tura interna dos países periféricos. Paulani demarca, assim, a década de 1970 como a primeira etapa da dominância financeira, onde a "periferia aparece como a demanda que faltava, num mundo em crise aberta depois do choque do petróleo, para a absorção da abundante oferta de crédito e liquidez então existente. (Idem, p.88).

Estes movimentos indicam a natureza de uma nova forma de dependência. Não mais a dependência como uma simples variável externa, mas como expressão interna do próprio capital, cujas relações entre classes e grupos mantinham estruturalmente a vinculação econômica com o exterior. Não surgiria, então, daí, uma nova etapa de desenvolvimento como proclamava o discurso dominante. Os índices de crescimento, a partir da industrialização dos países periféricos, apenas respondiam à plataforma de valorização que começava a surgir.

A crise do capital, instalada a partir de 2008 , tem repercutido de forma generalizada nos países periféricos e centrais, mas nestes últimos, como Estados Unidos e Europa, tem-se produzido uma combinação de baixo crescimento com distribuição desigual da renda. Na contramão dos países centrais, que seguem desestruturando seus sistemas de bem-estar social, e retrocedendo em direitos sociais, o Brasil tem buscado qualificar suas históricas políticas compensatórias na tentativa de responder às orientações dos organismos multilaterais (BID, Bird e FMI) e configurar-se como uma potencial economia desenvolvida, que concilia destacados índices de crescimento econômico e de inclusão social.

A busca incansável do crescimento econômico flexiona a lógica de "máximo para o econômico e mínimo para o social", base da ideologia neoliberal, para passar a assentar-se na ideia de um "capitalismo humanizado" sem, no entanto, romper com o conservadorismo, que é base da formação social, econômica e política brasileira. Trata-se de um novo projeto político e econômico em desenvolvimento, mais precisamente, a partir do segundo mandato do governo do, então, presidente Luiz Inácio da Silva, buscando equilibrar crescimento econômico e desenvolvimento social.

As políticas de ajuste revelam as contradições do sistema do capital, consubstanciadas na instabilidade, na insegurança, na liquidez, na precarização estrutural do trabalho, nas exclusões crescentes, na descartabilidade e na desestruturação do Planeta. A crise estrutural encarna a insustentabilidade do sistema do capital nesta nova temporalidade histórica. Em um contexto de crise, recessão e agravamento da Questão Social emerge a perspectiva do desenvolvimento, ressignificada, em meio às políticas de ajuste. É o neodesenvolvimentismo como um fenômeno do século XXI (Castro, 2013). 
A partir do primeiro mandato do governo Lula, elementos do novo modelo de orientação capitalista tendo como referência o chamado "novodesenvolvimentismo" ou "neo-desenvolvimentismo", são evidenciados de forma mesclada à política neoliberal. Tal modelo opera com foco nos desenvolvimentos econômico e social. Sob a fachada de um "capitalismo humanizado", o novo-desenvolvimentismo prega o crescimento econômico atrelado, e em equilíbrio com a expansão do social.

A dimensão ideológica tem forte peso neste reordenamento social, que, amparando-se na ideia de capital humano, dissemina um novo ideário para o trabalho, a educação e para a própria individualidade. "A ênfase será dada à capacidade e à competência que cada indivíduo deve adquirir no mercado educacional para atingir melhores condições de disputa e melhor posição no mercado de trabalho" (Idem,p. 19).

A teoria do capital humano se fixa na iniciativa individual, enquanto a teoria do capital social, que a complementa, ressalta o fortalecimento das instituições através de uma cultura cívica que estimula a ajuda mútua. Ações individuais convergem para um processo de criação de redes de solidariedade, amparadas nas instituições, gerando legitimidade e hegemonia para se alcançar o desenvolvimento local focado nas comunidades mais carentes.

As políticas compensatórias, contemporaneamente destacadas no âmbito das políticas sociais, são reflexos deste novo ciclo de reordenamento do capital, que tem no Estado uma intervenção mais atuante na extrema pobreza. Sob a ótica de equilibrar crescimento econômico e desenvolvimento social, o Brasil tem dado ênfase às políticas de transferência de renda, e segue no seu percurso de buscar o desenvolvimento econômico, desta feita, como país emergente que tem alcançado, nos últimos anos, patamares satisfatórios na economia mundializada.

Trata-se de uma tentativa de alcançar o tão propalado "crescimento sustentável". A nova estratégia do capital proclama que os patamares satisfatórios de crescimento econômico serão mantidos com a ampliação do consumo, a fim de fortalecer o mercado. E isso só acontecerá com um certo atendimento das necessidades sociais, o que exige um conjunto de políticas e programas sociais voltados para minorar a pobreza e reduzir as desigualdades sociais. 
O incremento das políticas sociais deve ser conduzido em articulação com um conjunto de orientações e estratégias, formatando uma nova cultura cívica e uma nova sociabilidade que instauram novas tendências de comportamento e de relações sociais.

Neste contexto de expansão do social são privilegiados os programas de transferência de renda, visando o combate à pobreza e à desigualdade social. O assistencial ganha impulso e centralidade no âmbito das políticas sociais, que já vinham sofrendo um processo de privatização.

No mercado ampliado estão disponíveis não só bens de consumo, mas bens sociais. A chave de inflexão do neoliberalismo para o novo-desenvolvimentismo, neste processo, é focar nos bens de consumo, preparando o mercado para que estes estejam ao alcance das classes pauperizadas.

Os bens sociais, que são, em grande medida, as políticas sociais privatizadas, podem ser acessados apenas por àqueles em condições de adquiri-los. Os bens sociais de maior qualidade localizados no mercado, estão assim, indisponíveis aos pobres, que podem continuar dispondo de políticas sociais públicas de baixa qualidade.

Os bens de consumo, estes sim, estão disponíveis aos pobres, que através de transferência de renda, podem "escolher" o que comprar no mercado com seu mínimo social. A pobreza é combatida, desta forma, no âmbito do mercado e não no campo social, reduzido às políticas sociais caras. Trata-se de uma estratégia do capital em fortalecer o mercado e pacificar a pobreza, que se sente privilegiada com certo grau de autonomia para "vencer por si só". Uma nova cultura cívica finca uma sociabilidade centrada no individualismo e na competição, já que as oportunidades estão dadas, cabendo aos indivíduos aproveitá-las.

O lócus do mercado ampliado, onde transitam distintos interesses, demandas e classes, paira, ideologicamente, como o centro de referência das distâncias sociais diminuídas. A exacerbação da ideologia do direito ao consumo simula uma certa "integração" social, que, na realidade, é uma "inclusão forçada" com fins de estimular o mercado.

A participação periférica dos beneficiários dos programas de transferência de renda no mercado é a meta consumada pelo capital e não a participação engendrada pela condição de cidadania alcançada pelos trabalhadores, a partir de suas conquistas civilizatórias. 


\section{As reconfigurações do trabalho no Brasil do século XXI: cenários do mundo laboral no processo de redefini- ção do capitalismo}

\subsection{As dinâmicas dos mercados de trabalhos}

Os novos processos de acumulação e valorização do capital, circunscrever um novo momento do capitalismo, impõem reconfigurações no mundo do trabalho. Vivencia-se distintos ciclos de ajuste à esta nova ordem do capital, com implicações em processo de reestruturação produtiva. Especificamente no Brasil, em seu processo tardio e intenso de ajustamento ao sistema do capital, começam a se efetivar profundas mudanças no mundo do trabalho a partir de 1990.

A experiência brasileira do ajuste, em consonância com as premissas neoliberais impõe a revisão do papel do Estado e um conjunto de desregulamentações econômica, financeira e comercial. O país começa, a partir daí, a assumir novo padrão de inserção na divisão social do trabalho no mundo globalizado, com impactos regressivos nos direitos trabalhistas e alterações significativas do mercado de trabalho. Os anos de 1990 são, portanto, o marco de profundas alterações nos campos produtivo e financeiro, com a interrupção de um ciclo de desenvolvimento econômico de quase cinco décadas com distintas configurações em diferentes conjunturas sociopolíticas.

Nos circuitos do ajuste, emerge o fenômeno do desemprego estrutural, organicamente vinculado à precarização do trabalho, ao longo de processos denominados de reestruturação produtiva, com expressões peculiares no âmbito da classe trabalhadora. Ao analisar os percursos da reestruturação do mundo do trabalho na vida brasileira, Pochmann (2008) oferece uma fecunda via analítica, demarcando a dinâmica de constituição do próprio mercado de trabalho. Segundo ele, no cenário do desenvolvimento capitalista no Brasil, pode-se bem delinear dois momentos históricos: (1930-1980) e (1980-2000).

De 1930 a 1980, verifica-se uma estruturação, ainda que incompleta, do mercado de trabalho. A indústria brasileira teve importante papel na estruturação do mercado de trabalho, quando o país, no início da década de 1930, tinha como projeto o desenvolvimento de uma produção nacional. Para tanto, era imperativo, naquele momento, forjar as bases sociais de organização do trabalho, criando as condições objetivas para a constituição de uma massa assalariada a ser empregada nos polos industriais. O início da estruturação do mercado 
de trabalho no Brasil, significava, assim, a consolidação das relações capitalistas de produção, tendo como base o desenvolvimento da indústria nacional. A massa de trabalhadores era composta pela mão de obra operária, bem como pelos assalariados da administração pública, que, naquele momento, se expandia em função da constituição do modelo de administração burocrática com a criação de ministérios, grandes empresas e órgãos da burocracia estatal.

Com o impulso da indústria, a economia brasileira, diversifica-se, mas permanece fincada em suas bases agroexportadora, onde a mão de obra rural permaneceria, até os anos 1960, sem nenhuma regulação trabalhista. Em todo o ciclo da industrialização nacional grande parcela da população, tanto do campo quanto da cidade, ficou excluída do emprego protegido.

A estruturação do mercado de trabalho, no Brasil, se processava, assim, de forma incompleta, e sem apontar para os moldes de uma sociedade salarial nos termos de Castel (1998). Para Pochmann, não houve uma homogeneização dos empregos, nos níveis constatados nos países desenvolvidos, permanecendo os problemas tradicionais do mercado de trabalho em economias subdesenvolvidas, como informalidade, subemprego, baixos salários e desigualdade de rendimentos (Pochmann, 2008,p.65).

A partir de 1980 aos anos 2000, tem-se o fenômeno da desestruturação do mercado de trabalho. A instabilidade e a precariedade, que configuram, estruturalmente, o trabalho no Brasil, se acirraram, então, a partir dos anos de $1980 \mathrm{com}$ a fase de desestruturação do mercado de trabalho e a grave crise do capital, que rompe com o projeto de crescimento econômico sustentado. Estava instalado, assim, o cenário de atenuação do processo de industrialização, com queda das ocupações dos setores primário e secundário da economia e inchamento do setor terciário.

$\mathrm{Na}$ última década do século XX - marco da experiência do ajuste brasileiro e da desestruturação do mercado de trabalho - acirram-se e reconfiguramse as históricas relações trabalhistas precárias, ao lado do aumento do nível do desemprego. Institui-se, então, uma legislação para regular estas formas instáveis de trabalho e diversificar os assalariamentos no contexto da Reforma do Estado. Destacam-se, no conjunto destas legislações, uma portaria do Ministério do Trabalho e um enunciado do Tribunal Superior do Trabalho, em 1995, favorecendo a proliferação da terceirização do emprego. Em 1996, forma introduzidos o contrato de contrato assalariado especial para micro e pequenas empresas (CLT simples) e o contrato temporário de contrato reformulado (CLT PT). Em 1998, foram implementados o contrato por tempo determinado (CTD) e o contrato por jornada parcial de trabalho (CPT). Em 1999, o setor 
público passa a dispor de uma lei que flexibiliza a demissão por excesso de pessoal. Em 2003, no âmbito do Contrato de Trabalho Primeiro emprego (CTPE), o número de contratados na faixa de 16 a 24 anos de idade não poderia ultrapassar o limite máximo de $20 \%$ do total de funcionários, nem substituir os contratos formais no interior da mesma empresa. As empresas passaram a contar com subsídio financeiro de $\mathrm{R} \$ 1.500,00$ a partir do emprego de um jovem de 16 a 24 anos. (Pochmann, 2008, p.21).

As medidas de diminuição do "custo trabalho" para alavancar o setor privado com estímulos por parte do Estado, em detrimento da estabilidade dos direitos do trabalhador, formatam um mercado de trabalho altamente desregulado e flexibilizado. Vê-se, assim, que o capitalismo flexível (Sennett, 2012), começa a emergir na década de 1990, com a desaceleração do crescimento econômico, solapando formas regularizadas e regulares de assalariamento, que eram expressões da fase estruturada do mercado de trabalho, associada à era do capital monopolista, impulsionado pelo projeto de desenvolvimento da indústria nacional.

As diferentes dinâmicas do mercado de trabalho estão associadas às mudanças do modelo de desenvolvimento, ao modo de inserção na divisão internacional do trabalho e às políticas macroeconômicas. No caso brasileiro, a indústria tem tido papel de destaque na composição ocupacional, nos rendimentos e nas novas formas de contratação e uso da força de trabalho. Vale ressaltar, entretanto, que a partir da década dos anos 2000, a tentativa de se reaver um projeto de desenvolvimento sustentável, teve como referência não o capital industrial, mas o capital financeiro.

\subsection{Informalidade}

O capitalismo periférico e tardio brasileiro de inserção subordinada e dependente ao capitalismo de países desenvolvidos, formatou, no seu processo de desenvolvimento, relações de trabalho com reduzida dimensão de regulação e regularidade, considerando o excedente da força de trabalho, que, de forma estrutural, se manteve à margem de relações formais de trabalho. A informalidade é, portanto, um traço peculiar das economias subdesenvolvidas, que sempre tiveram no excedente da força de trabalho, a referência para a organização e o funcionamento de mercados de trabalho.

A informalidade, como expressão de trabalho não protegido, enseja processos de exploração da força de trabalho e de sujeição do trabalhador ao 
capital. No campo da informalidade estão, permanentemente, no curto ou longo prazos, à disposição dos interesses do capital, os desempregados e os que vivem à margem das atividades capitalistas, desenvolvendo ações estratégicas de sobrevivência ("massa marginal de trabalhadores e de desempregados ocultados pelo desalento ou pelo trabalho eventual e precário") (Pochmann, 2008, p.197).

Há de se registrar, inclusive, que na história da formação social, econômica, política e cultural de nossa sociedade não houve ruptura com o trabalho servil. O baixo estatuto do trabalho, no Brasil, é característica da sua economia, mas tende a se acirrar em tempos de crise do capital. A última grande crise de 2008, cujos desdobramentos, estamos, ainda, a viver, apontaram para novas questões no campo do trabalho de maneira a redimensionar este baixo estatuto. A revolução tecnológica é uma destas novas questões, a partir da qual se esboçam novas modalidades de controle de exploração da força de trabalho.

As redefinições do mundo do trabalho estão fundadas na extrema tecnologização e em novas configurações ideológicas. Como o chão da fábrica desaparece, disseminando os processos de trabalhos em espaços múltiplos e diferenciados, o poder do capital tende a se tornar invisível, deixando de ser uma realidade sensível de exploração (Teixeira, 2013). Relacionados aos novos processos de trabalho, os mecanismos de controle social ganham novos formatos, embora a alienação continue a ser um dos objetivos do capital na sua relação com a classe trabalhadora. A captura da subjetividade do trabalhador no processo de trabalho alienante e produtivista tem sido objeto de inúmeros estudos, que abordam os tipos de adoecimento dos trabalhadores gerados por tais processos nos quais não há mais os limites entre os tempos do trabalho e do não trabalho (Dejours, 1987); (Rosso, 2008).

\subsection{A Intensificação}

Uma das peculiaridades e dos paradoxos da última grave crise do sistema do capital em tempos de globalização é a revolução da tecnociência. O salto na criação material com as Revoluções na Informática e nas Comunicações tende a exacerbar a dimensão ideológica do capital, a fim de escamotear o alto cus to que a humanidade paga por estas mudanças radicais, determinando novas formas de controles e de exploração: a destruição da natureza, o crescimento da barbárie, das desigualdades sociais, a intensificação do trabalho.

No capitalismo contemporâneo, a análise da intensidade do trabalho está voltada para o aumento quantitativo e qualitativo dos resultados, quando se demanda um consumo maior de energia do trabalhador (do corpo e /ou da 
mente). Ou seja, para Rosso, intensidade é mais que esforço físico, "pois envolve todas as capacidades do trabalhador, sejam as de seu corpo, a acuidade de sua mente, a afetividade despendida ou os saberes adquiridos através do tempo ou transmitidos pelo processo de socialização" (Rosso, 2012, p.21). Em suma, mais intensidade significa mais trabalho, para produzir mais e melhores resultados.

Rosso analisa os fatores que condicionam a intensidade, através da noção de produtividade, como forma, inclusive, de distinguir intensidade e produtividade do trabalho. Há produtividade, quando o aumento dos resultados decorre de avanços efetuados tão-somente nos meios materiais com os quais o trabalho é realizado. A noção de produtividade restringe-se ao efeito das transformações tecnológicas. Já a intensidade exige maior envolvimento e desgaste do trabalhador, quando se utiliza ou não, máquinas de última geração.

Com o avanço tecnológico, é exigência do trabalho contemporâneo, que o trabalhador se adapte e tenha domínio dos equipamentos de última geração, dos novos processos burocráticos e de racionalização do trabalho, sendo necessário, para isso, maior envolvimento e dispêndio de energia (capacidade intelectual) para a produção desejada. As atividades, hoje, passam a incorporar crescentemente tecnologias de informática, de comunicação, de automação, requerendo um conjunto maior de capacidades da inteligência, da afetividade e do conhecimento. A intensidade é, assim, uma noção associada tanto ao trabalho material (produção concreta), quanto aos mais recentes processos de produção, relativos às novas ocupações, concentradas, no campo do trabalho imaterial.

O que vemos de novo, na dinâmica atual do trabalho, é o seu processo de intensificação, atingindo o setor de serviços, e produzindo efeitos nocivos à saúde dos trabalhadores, ou, para ser mais preciso como Rosso, à saúde da "classe dos trabalhadores imateriais intensificados" (Rosso, 2012, p.31).

Os trabalhadores do setor de serviços, em número cada vez maior, em função da expansão deste setor, passam, a serem, cada vez mais, cobrados por mais envolvimento e mais resultados, através de processos de intensificação do trabalho. As atividades não-materiais estão, assim, completamente inseridas no processo de reestruturação produtiva, que aumenta a dimensão da precarização do trabalho.

Cabe aqui, nos determos na ideia de flexibilização, que ao lado das noções de informalidade e intensidade, consubstanciam o processo de reestruturação produtiva, apresentando-se como componentes de novas estruturas do sistema de poder. Contudo, se entendemos como Salermo, que flexibilização é a capacidade de responder adequadamente às mudanças, observamos a sua exis- 
tência há muito tempo no Brasil, através de inúmeros acordos possíveis entre patrões e empregados em torno da carga de trabalho (compra de férias, trabalho noturno, férias coletivas, facilidades nos processos de demissão entre outros) (Salermo, 1989). A flexibilização é assim, um processo que vem se acentuando no Brasil.

Para Sennett, a repulsa à rotina burocrática e a busca de flexibilidade produziram novas estruturas de poder e controle, levando à: reinvenção descontínua das instituições, especialização flexível de produção e concentração de poder sem centralização. A reinvenção descontínua das instituições se dá por meio da chamada "reengenharia de produção", que consiste numa nova estrutura organizacional mais compacta e reduzida, tanto de trabalhadores, quanto de funções, com metas de maior produtividade e lucratividade. Com a especialização flexível, busca-se colocar, cada vez mais rápido, produtos mais variados no mercado, visando uma produção melhor planejada. Já com a concentração sem centralização compreende, em teses, a descentralização do poder, a fim de que os ocupantes de cargos inferiores sejam controladores de seu próprio trabalho. Mas, na prática, os altos administradores têm um quadro abrangente e detalhado sobre as realizações de seus subordinados, através dos sistemas de informação (Sennett, 2012). O trabalho em rede, tendo como suporte a tecnologia, tem produzido uma "reengenharia", a fim de reduzir o número de administradores sobre um número maior de subordinados, com isso, a redução de empregos.

Tais características oferecem uma visão da reestruturação produtiva do capitalismo mundializado, cujo modelo de organização mais flexível se adéqua aos novos padrões de produção e acumulação. Contudo, não se trata de um processo uniforme e linear, considerando-se as particularidades e as diferenças de cada país e continente.

O processo de reestruturação produtiva se intensificou, no Brasil, a partir da década de 1990, comportando elementos, tanto de continuidade, quanto de descontinuidade em relação às fases anteriores. Através de suas pesquisas sobre a implantação deste processo no Brasil, Antunes constatou uma mescla nítida entre elementos do fordismo periférico e subordinado, com uma vigência ainda acentuada, e elementos oriundos das formas de acumulação flexível e/ou influxos toyotistas, igualmente evidentes.

Na passagem dos anos de 1980 para os anos de 1990, dá-se, assim, uma mutação significativa dos processos produtivos, dentro da lógica instrumental do mundo empresarial, determinando a redução do trabalho protegido com a crescente onda de desregulamentação das relações de trabalho. Trata-se da era 
da informatização do trabalho a presenciar a época da informalização do trabalho, caracterizada pela ampliação de empresas terceirizadas e de trabalhadores temporários, subcontratados, flexibilizados (Antunes, 2011, p.133).

Contemporaneamente, o desenvolvimento das novas tecnologias da informação e da comunicação impõe um ritmo da "urgência", da "imediaticidade", tornando o tempo do trabalho acelerado. Assim, cabe ao trabalhador administrar seu tempo de trabalho, que, em ritmo cada vez mais ágil, dada as várias tarefas, polivalência, flexibilidade e intensificação, tende a ocupar seu "tempo de não trabalho" com suas atividades laborais. O tempo de trabalho passa a entrar em assincronia com os tempos de lazer, da família, do descanso, entre outros.

Como há incertezas em relação ao futuro, já que as ocupações estão cada vez mais instáveis e precárias, o tempo presente reina como o tempo absoluto. A obsessão contemporânea é a corrida contra o tempo, levando os trabalhadores a serem amealhados por múltiplas tarefas, ao lhes exigirem uma produtividade maior, ou por terem apenas, como opção ao desemprego, ocupações fragmentadas. A cobrança de ser rápido e de estar sempre focado é a base ideológica do sistema de capital, que transforma empregados em "colaboradores", "parceiros" do mesmo negócio. Os mecanismos de controle se sofisticam, tornando invisíveis as formas de exploração. $\mathrm{Na}$ verdade, a cobrança por melhores e maiores resultados é internalizada pelos próprios trabalhadores, que se tornam seus próprios algozes, evidenciando-se a captação da subjetividade do trabalhador. O custo de tudo isso, portanto, é pago por suas vítimas com tensões física e psicológica, bem como adoecimentos, expandidos para diferentes camadas e classes sociais.

A ampliação e a intensificação dos processos flexíveis de trabalho, tendem a universalizar a vulnerabilidade, anteriormente restritas aos segmentos à margem das relações formais de trabalho. Contudo, a integração ao mercado de trabalho se dá, contemporaneamente, de forma instável, dada, entre outros fatores, à acirrada competição, que leva a uma alta rotatividade dos postos laborais. Os baixos salários são, também, fontes de insegurança para o trabalhador, indicando um aumento da desigualdade no mercado de trabalho, onde há um restrito nicho altamente especializado com elevados salários e uma expansão de empregos assalariados com baixas remunerações.

Ao abordar a nova cultura do capitalismo em tempos flexíveis, Sennett fala sobre o sentimento de fracasso, que não é mais uma perspectiva apenas dos muito pobres ou desprivilegiados, atingindo as classes médias como um fator regular: "As reduções e reengenharias impõem às pessoas da classe média tragédias, que nos primeiros tempos do capitalismo ficavam muito mais limitadas às 
classes trabalhadoras" (Sennett: 2012, p.135).

\section{Novas configurações na estrutura social}

$\mathrm{Na}$ esfera ampliada do trabalho flexível, intensificado e terceirizado, ganha relevo os processos de sociabilidade inerentes às estas formas de trabalho precarizado, com o seu conjunto de valores, signos e comportamentos. As configurações contemporâneas do capitalismo no Brasil, centradas no ideário neoliberal, ensejam uma nova sociabilidade pautada nos preceitos do individualismo competitivo e agressivo.

Os processos de incorporação destes preceitos se dão, de forma ampla, e com tendências homogêneas, no conjunto das classes sociais. A "nova classe trabalhadora", forjada no contexto de economia neoliberal, segundo Chauí (2003), tem uma propensão a assumir estas referências, levando-a a uma aproximação com o ideário que sustenta a chamada "classe média". Diferentes autores apresentaram conceitos diversos - "nova classe trabalhadora", "nova classe média", "batalhadores sociais", "precariado" - para definir esta "classe social dos emergentes". É de fato uma nova classe ou a redução dos níveis de pobreza, instaura novas configurações na estrutura da clássica divisão, situandoas entre as classes $\mathrm{A}$ e E?

Houve tanto um processo de proletarização da classe média tradicional, levando-a, em grande parte, a se disseminar na classe trabalhadora, quanto um deslocamento de segmentos pauperizados para a classe trabalhadora. Por proletarização da classe média, entendemos a fragilização das relações e das condições de trabalho. Apesar da existência de empregos formais, a classe média perdeu, na sua grande maioria, seu status econômico e social, em função da baixíssima qualidade destes empregos, tanto do ponto de vista da remuneração, quanto das condições de trabalho.

A integração social via esforço individual, expressando satisfatórios patamares de qualidade de trabalho e de vida, é um indicador histórico e central da classe média, que, para a sua reprodução, necessita de um trabalho seguro e protegido. Com a precarização das relações de trabalho, o status da classe média tendeu a decair, havendo uma mobilidade descendente, e um alargamento da classe trabalhadora, cada vez mais fragmentada, embora, atuante no mercado, como consumidora.

Além de salários rebaixados, este contingente precarizado de classe média arca com serviços sociais como educação, saúde, previdência, entre outros. 
E, a partir das políticas de ajuste, nos anos de 1990, acentuadamente, foram privatizados como novas formas de valorização do capital.

As formas de integração social, que é uma referência central das classes média e trabalhadora, acentuam-se na sua dimensão marginal, no âmbito das medidas de ajuste e políticas neoliberais no Brasil, já que o tipo de integração, mesma na era fordista, já era periférica. Para aprofundar a discussão sobre a integração social, recorremos a Polanyi que nos apresenta duas grandes referências de unidade e estabilidade dos processos econômicos: formas de integração e Princípios de comportamento. A primeira, designa formas de inserção consciente e autossustentada na sociedade com fonte de renda e aspirações, próprias da velha classe média. A segunda, diz respeito aos comportamentos e atitudes passivas de indivíduos que copiam comportamentos de grupos que lhes servem de espelho, que são comuns aos membros da classe proletária, que almeja ascender socialmente.

Estas novas configurações, resultantes do processo de reestruturação produtiva, nos anos de 1980no Brasil, que precarizam as relações de trabalho, fragmentando a força de classe do operariado, não leva, contudo, a nosso ver, a uma "nova classe trabalhadora". Trata-se da mesma classe trabalhadora, que ganha novos contornos em função de um novo ciclo do capital, agudizando a sua condição de existência, e, contraditoriamente, mascarando uma pseudocondição de ascensão, tão decantada na emergência de "uma nova classe média". A melhoria da condição econômica e social de um grande segmento social pobre, com a elevação real do salário mínima e dos programas de transferência de renda, leva a uma ampliação da classe trabalhadora, que passa a absorver este contingente de empregados formais, flexíveis, temporários, terceirizados. E vale lembrar que é frágil este tipo de inserção no campo do trabalho, por parte deste segmento emergente, que o integra perifericamente, sem as garantias de direitos. A face frágil desta forma de integração é o assistencialismo, e não o trabalho como um direito social.

\section{Referências}

ANTUNES, Ricardo. A substância da crise. Introdução. In: MĖSZÀROS, I. A crise estrutural do capital. São Paulo: Boitempo, 2011. p.8 .

O Continente do labor. São Paulo: Boitempo, 2011.

BRAGA, Ruy. A Política do precariado: do populismo à hegemonia lulista. São Paulo: Boitempo, 2012. 
. O feitiço do camarote. Net, nov. 2013. Disponível em: < $\underline{w w w .-}$ blogdaboitempo.com.br/category/colunas/Ruy-braga/>. Acesso em: 12 nov. 2013. OK

. Novas classes perigosas?. Net, fev. 2014. Disponível em:

< http://blogdaboitempo.com.br/2014/02/14/nova-classe-perigosa/>. Acesso em: 20 fev. 2014.

CARDOSO, Ana Cláudia. Tempos de trabalho, tempos de não trabalho.

Disputas em torno da jornada do trabalhador. São Paulo: Annablume, 2009.

CARDOSO, Fernando Henrique eFALETTO, Enzo. Dependência e desenvolvimento na América Latina: Ensaio de Interpretação Sociológica. 7. ed. Rio de Janeiro: Editora LTC, 1970.

CARVAlHO, Alba Maria Pinho de. Políticas Públicas e o Dilema de Enfrentamento das Desigualdades: Um Olhar Crítico sobre a América Latina no Século XXI. In: SOUSA, Fernando José P.(org.). Poder e Políticas Públicas na América Latina. Fortaleza: Edições UFC, 2010.

CASTEL, Robert. As metamorfoses da questão social. Petrópolis: Vozes, 1998.

CASTELO, Rodrigo. O novo desenvolvimentismo e a decadência ideológica do pensamento. Serviço Social e Sociedade, n. 112, p. 613-636, 2012.

CASTRO, Alba Tereza B. de. Novo Desenvolvimentismo e a Nova Face das Políticas Compensatórias. In: Jornada Internacional de Políticas Públicas, VI. [Anais...]. São Luiz: UFMA, 2013.CD-ROM.

CHAUÍ, Marilena. Entrevista. Revista Cult, n. 182, 2013.OK

DEJOURS, Christophe. A loucura do trabalho. Estudo de Psicopatologia do Trabalho. São Paulo: Cortez, 1987.

GONÇALVES, Reinaldo. Novo Desenvolvimentismo e Liberalismo enraizado.Serviço Social e Sociedade,n.112, p. 637-671, 2012.

PAULANI, Leda Maria. A inserção da economia brasileira no cenário mundial: uma reflexão sobre a situação atual à luz da história. Boletim de Economia e Política Internacional, IPEA, p. 89-102, 2010.

PAULANI, Leda Maria. Brasil Delivery. São Paulo: Boitempo, 2008.

. A dependência redobrada. Le Monde Diplomatique. Edição Brasileira. Agosto de 2012. 
POCHMANN, Marcio. O emprego no desenvolvimento da nação. São Paulo: Boitempo, 2008.

POLANYI. Karl. A grande transformação. Rio de Janeiro: Ed, Campus, 2000.

REIS, Elisa P. As Ciências Sociais e o bug do milênio. Revista Brasileira das Ciências Sociais, v.14, n.39, p. 05-11, 1999.

ROSSO, Sadi Dal. Mais Trabalho! A intensificação do labor na sociedade contemporânea. São Paulo: Boitempo, 2012.

SALERMO, Mário Sérgio. Automação flexível, gestão do tempo e processos de trabalho na indústria. Revista Engenharia de Produção, n. 2, p.26-38, 1989.

SENNETT, Richard. A corrosão do caráter. O Desaparecimento das virtudes com o capitalismo. Rio de Janeiro: Best Bolso, 2012.

STANDING, Guy. The precariat: The New Dangerous Class.Londres:Bloomsburry, 2011.

TEIXEIRA, Francisco. Redimensionamento da crise do capital: o público, o privado e as políticas sociais. Net, mar. 2013. Disponível em: $<$ franciscojoseteixeira.blogspot.com.br>. Acesso em: 03 mar. 2013.

TELLES, Vera da Silva. Transitando na linha de sombra, tecendo as tramas da cidade. In: Oliveira, Francisco e Rizek, Cibele (org.). A era da indeterminação. São Paulo: Boitempo, 2007. p. 216.

THE ECONOMIST. The BRICs: The trillion-dollar club.Net, dez. 2013.

Disponível em: < http://www.economist.com/world/international/displaystory.cfm?story id=15912964> . Acesso em: 05 dez. 2013.

WILHANS, Alex.A crise capitalista de 2007-2009. As interpretações marxistas. Entrevista especial com Alex Wilhans. Net, jun. 2013. Disponível em $<$ www.ihu.uisinos.br/entrevistas/508533-marxistas-examinam-a-crise-entrevista-especial-com-alex-wilhans $>$. Acesso em:10 jun.2013. 
